\title{
Per què a l'estiu fa calor?
}

\author{
Virgina Larraz Rada (vlarraz@uda.ad) Universitat d'Andorra. \\ Florenci Pla Altisent (fpla@uda.ad) Universitat d'Andorra.
}

El projecte es basa en la resolució d'una gran pregunta enigma: Per què a l'estiu fa calor?, que en principi sembla molt òbvia, però que no ho és tant. La recerca de la solució portarà a desmuntar creences socialment acceptades que no tenen la credibilitat de la ciència. El mètode de treball ha buscat involucrar els estudiants en pràctiques científiques. A partir d'una sèrie d'hipòtesis recollides mitjançant una enquesta, es duen a terme una sèrie d'experiments que han aportat dades objectives, les quals han permès arribar a unes conclusions que donen resposta a la pregunta plantejada.

Paraules clau: experiments d'ensenyament, clima, tutoria entre iguals.

The project is based on solving a mystery question: Why does the summer heat? which initially seems very obvious, but it is not so. The research will lead to the solution of dismantling socially accepted beliefs that do not have the credibility of science. The work method has pursued to involve students in scientific practices, which, based on a series of assumptions collected through a survey, carried out a series of experiments that have provided objective data, which have allowed it to reach conclusions respond to the question posed

Keywords: Teaching experiments, weather, Peer tutoring.

\section{SITUACIÓ DE L’EXPERIÈNCIA}

Com a professors del bàtxelor en Ciències de l'educació de la Universitat d'Andorra; ens dediquem a formar futurs mestres. Amb les nostres assignatures promovem que els estudiants siguin creatius, que esdevinguin dissenyadors de situacions d'aprenentatge en què els nens i les nenes puguin experimentar sent partícips del propi procés de construcció del coneixement; en resum, que siguin capaços de promoure un aprenentatge actiu. Hem volgut fer un pas més, sortir de les aules universitàries i posar en pràctica allò que prediquem. La convocatòria del I Premi Maria Geli va ser l'excusa perfecta per transferir la nostra filosofia al Col-legi M. Janer.

El projecte Per què a l'estiu fa calor? es va desenvolupar a les aules d'Infantil, Primària i Secundària del Col·legi M. Janer del Principat d'Andorra en el curs escolar 2014-2015. Hem desenvolupat aquest projecte basant-nos en tres fonaments: l'aprenentatge de la ciència des de l'experimentació (Valverde, 2014), els experiments d'ensenyament
(Molina, 2011) i la potencialitat de la tutoria entre iguals (Rodríguez, 2000), quan els iguals són alumnes d'edats diferents (Pujolàs, 2002; Durán, 2004).

El mètode de treball ha buscat involucrar els estudiants en pràctiques científiques. A partir d'una sèrie d'hipòtesis nascudes dels coneixements preconcebuts i recollides mitjançant una enquesta, es duen a terme una sèrie d'experiments que han aportat dades objectives, les quals han permès arribar a unes conclusions que donen resposta a la pregunta plantejada

\section{L'EXPERIÈNCIA}

\section{El punt de partida.}

Els alumnes de $3 r$ de primària van fer una enquesta amb la pregunta següent: Per què a l'estiu fa calor? Els camps de l'enquesta van ser: Edat, entorn (alumne del mateix col-legi, familiar, estudiant batxillerat/UdA, altres) i resposta (oberta). Per dur a 
terme la tasca, cada alumne havia de passar l'enquesta a dues persones.

Els estudiants de $4 \mathrm{t}$ de secundària, a partir de les enquestes, van concretar tres hipòtesis que serien les seleccionades per analitzar al llarg del curs. Concretament:

1) Perquè estem més a prop del Sol

2) Perquè el dia és més llarg (hi ha més hores de Ilum solar)

3) Per que els rajos solars són més verticals (el Sol està més amunt)

\section{Les hipòtesis}

Per a cadascuna de els hipòtesis es va preparar una sèrie d'experiments que es recullen a la taula següent:

\begin{tabular}{|l|l|}
\hline \multirow{4}{*}{$\begin{array}{l}\text { HIPÒTESI (1): } \\
\text { Perquè estem més } \\
\text { a prop del Sol }\end{array}$} & $\begin{array}{l}\text { Experiment 1.1: Repre- } \\
\text { sentació del binomi } \\
\text { Terra-Sol a l'entorn del } \\
\text { col-legi }\end{array}$ \\
\cline { 2 - 2 } & $\begin{array}{l}\text { Experiment 1.2: Repre- } \\
\text { sentació d'una el-lipse }\end{array}$ \\
\hline \multirow{2}{*}{$\begin{array}{l}\text { HIPÒTESI (2): } \\
\text { Perquè el dia és } \\
\text { més llarg (més ho- } \\
\text { res de sol) }\end{array}$} & $\begin{array}{l}\text { Experiment 2.1: Estudi } \\
\text { del cas particular d'An- } \\
\text { dorra la Vella }\end{array}$ \\
\cline { 2 - 2 } & $\begin{array}{l}\text { Experiment 2.2: Estudi } \\
\text { d'altres ciutats }\end{array}$ \\
\hline \multirow{3}{*}{$\begin{array}{l}\text { HIPÒTESI (3): } \\
\text { Perquè els rajos } \\
\text { solars són més in- } \\
\text { clinats }\end{array}$} & $\begin{array}{l}\text { Experiment 3.1: Esfera } \\
\text { celeste a la taula }\end{array}$ \\
\cline { 2 - 2 } & $\begin{array}{l}\text { Experiment 3.2: Angle } \\
\text { d'incidència dels rajos so- } \\
\text { lars }\end{array}$ \\
\cline { 2 - 2 } & $\begin{array}{l}\text { Experiment 3.3: Llum i } \\
\text { ombra }\end{array}$ \\
\hline Taula 1: Relació d'hipòtesis amb els experiments
\end{tabular}

\section{Hipòtesi (1) Perquè estem més a prop del Sol}

Aquesta hipòtesi ens porta a estudiar el moviment de translació de la Terra al voltant del Sol (circular/el-líptic...). El moviment de la Terra al voltant del Sol es pot considerar pràcticament circular. La diferència entre la màxima distància Terra-Sol (152.000.000 km) i la mínima distància Terra-Sol $(147.000 .000 \mathrm{~km})$ ens permet observar que la diferència relativa és mínima (aproximadament un $3 \%$ ).
L'experiment 1.1 (representació del binomi Terra-Sol a l'entorn del col-legi) va requerir del següent material: cartró, paper i pintura (per fer sol); plastilina (per fer la Terra) ; corda llarga (uns 20m); regle i cinta mètrica. El procediment que es va seguir va ser el següent:

1) Calcular. Els alumnes de $2 n$ de secundària van calcular l'escala viable de reproducció. Van decidir treballar a una escala d'1:109. El resultat a què van arribar és que amb l'escala $1: 10^{9}$ el Sol té un diàmetre d'1,4 m; la Terra, un diàmetre d'1,3 cm, i la distància Terra-Sol és de $152 \mathrm{~m}$ (màxima -afeli-) i 147 m (mínima-periheli-).

2) Construir les maquetes. Els alumnes de $2 n$ de secundària van construir una esfera d'1,4 $\mathrm{m}$ de diàmetre (Sol). Els alumnes d'Infantil van decidir pintar l'esfera de color groc i la van representar la Terra fent amb una bola de plastilina $(1,3 \mathrm{~cm}$ de diàmetre).

3) Representar el binomi Terra-Sol a l'entorn de l'escola. Es va representar al carrer de l'escola, el Sol en un extrem i a una distància de $152 \mathrm{~m}$ la Terra (i un nen amb un cartell ESTIU) i a $147 \mathrm{~m}$ la Terra (i una nena amb un cartell HIVERN).

Els alumnes van arribar a la conclusió que la distància Terra-Sol no justifica en cap cas que a l'estiu faci calor a Andorra ja que és a l'estiu quan la Terra està més lluny del Sol.
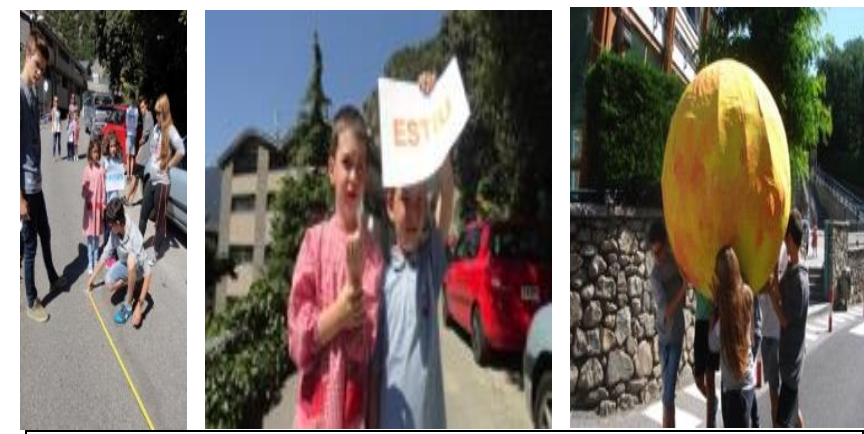

Figura 1: Representació al carrer del binomi TerraSol

A l'experiment 1.2 (representació d'una el·lipse) es va utilitzar el següent material: una corda de $2 \mathrm{~m}$ aprox., guixos de colors i cinta mètrica. Els estudiants de segon de secundària van dibuixar el-lipsis de diferent distància focal, seguint el sistema del jardiner sobre paper i al terra d'un pàrquing annex al Col-legi. Les conclusions a las que van arribar els alumnes foren 1)que la forma de l'el-lipse variaen funció de la distància entre els focus 2) com més 
junts estan els focus més s'aproxima a una circumferència 3) com que la distància Terra-Sol varia només un $3 \%$, els focus estan molt junts, i en conseqüència la conclusió a la qual van arribar és que la trajectòria de la Terra al voltant del Sol és pràcticament una circumferència, tal com van poder comprovar després de dibuixar les dues el-lipses.

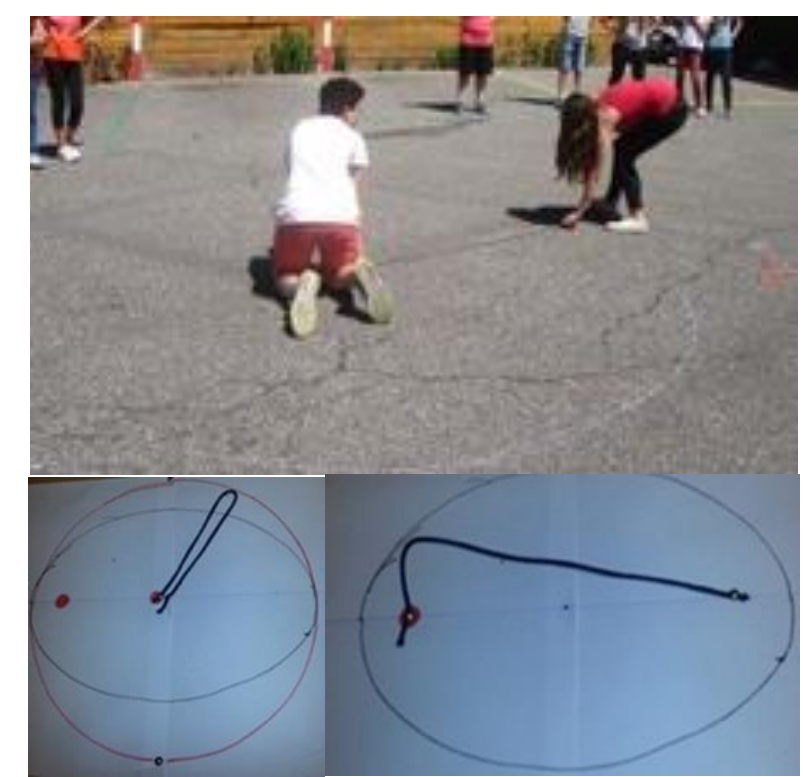

Figura 2. Dibuixant el-lipsis

\section{Hipòtesi (2): Perquè el dia és més llarg (més hores de sol).}

El fet que en un dia (24 hores) hi hagi una part que és de dia (llum solar) i una part que és de nit (absència de llum solar) es deu al moviment de rotació de la Terra sobre si mateixa. En canvi, la variació d'hores de llum solar al llarg de l'any es deu a l'orientació de l'eix de la Terra respecte al Sol en el moviment de translació de la Terra al voltant del Sol.

L'experiment 2.1 (estudi del cas particular d'Andorra la Vella) consistia en comprovar si hi ha una relació (lògica) entre: latitud ( $\mathrm{L}$ ), hores de llum solar $(\mathrm{H})$ i temperatura mitjana $(\mathrm{T})$ en el cas d'Andorra. El material que es va utilitzar va ser un ordinador amb accés a Internet i un full de càlcul (model de càlcul elaborat pel professor). El procediment que es va seguir va ser el següent:

1) Cercar. Els alumnes de 6è de primària van buscar a Internet les hores de llum solar a Andorra al llarg de tot l'any. Per simplificar-ho, només van recollir la informació d'un dia al mes (el 21 de cada mes). Els alumnes van haver de recordar com es passa del sistema decimal al sistema sexagesimal. També van buscar la temperatura mitjana de cada mes de l'any.

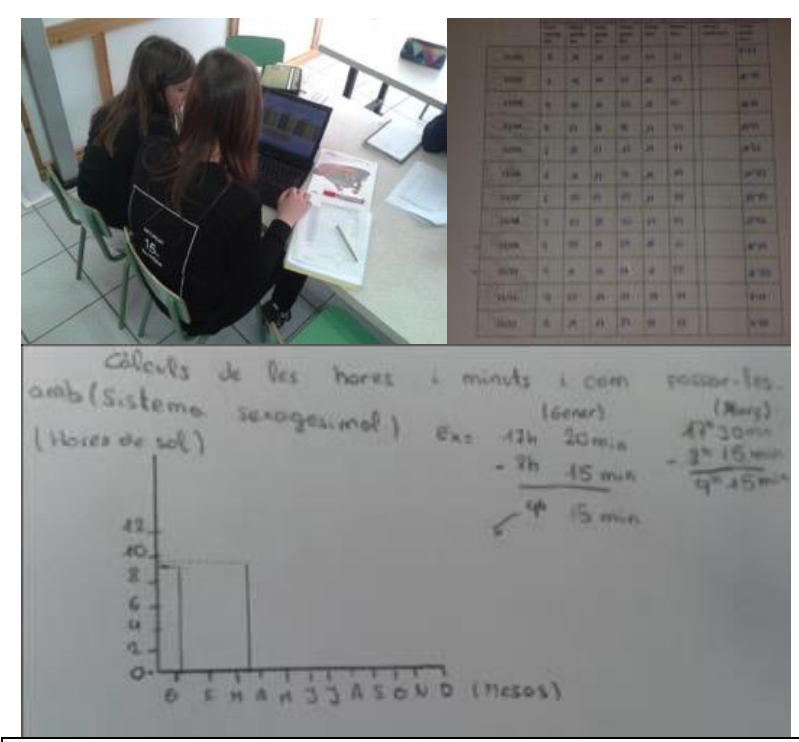

Figura 3. Alumnes de 6 è de Primària buscant informació a Internet i calculant hores de Sol.

\begin{tabular}{|c|c|c|}
\hline Mes & Hores de sol & ${ }^{\circ} \mathrm{C}$ \\
\hline Gener & 9,53 & 0 \\
\hline Febrer & 10,73 & 1 \\
\hline Març & 12,08 & 6 \\
\hline Abril & 13,55 & 12 \\
\hline Maig & 14,73 & 17 \\
\hline Juny & 15,30 & 22 \\
\hline Juliol & 14,90 & 25 \\
\hline Agost & 13,75 & 23 \\
\hline Setembre & 12,32 & 8 \\
\hline Octubre & 10,92 & 3 \\
\hline Novembre & 9,65 & hores sol \\
\hline Desembre & 9,07 & \\
\hline & & \\
\hline & & \\
\hline
\end{tabular}

Taula 2. Taula i gràfic que relaciona les variables estudiades d'Andorra la Vella.

2) Representar. Van representar la informació de la temperatura mitjana en gràfics que també recoIlien les hores de llum solar i la temperatura mitjana de cada mes. El fet de tenir tota la informació al mateix gràfic facilita la deducció de les conclusions. Amb aquest gràfic van deduir que hi ha 
una certa relació entre les hores de llum solar i la temperatura, ja que a mesura que augmenten les hores de llum solar augmenta la temperatura. On no hi ha coincidència és en els màxims de cada gràfic, ja que el màxim d'hores de llum solar s'assoleix al juny (21 de juny) i la màxima temperatura s'assoleix al juliol.

L'experiment 2.2 (estudi d'altres ciutats) tenia per objectiu comprovar si en altres ciutats es compleix la mateixa relació que a Andorra la Vella. Per això, van estudiar quatre ciutats més: dues de situades al nord d'Andorra (Reykjavík i Londres) i dues de situades al sud d'Andorra (Dakhla i Libreville). El materials utilitzats van ser un ordinador amb accés a Internet i un full de càlcul (model de càlcul elaborat pel professor). El procediment seguit va ser:

1) Cercar. Els alumnes de 6è de primària, tal com havien fet en el cas d'Andorra la Vella, van buscar a Internet http://www.tutiempo.net/calendario-solar/) (l'hora en què surt el Sol (h:min) i l'hora en què es pon (h:min) a les ciutats següents (el dia 21 de cada mes): Reykjavík, Londres, Dakhla i Libreville.

2) Calcular. Part de la informació que es necessita es troba a Internet, però n'hi ha que cal calcular, com és el cas de les hores de llum solar. Això ho van a dur a terme utilitzant un full de càlcul amb un model de càlcul facilitat pels mestres

3) Representar la informació en formats diferents. Van passar les hores de llum solar calculades a un gràfic i les van comparar. De l'observació es dedueix que el 21 de març i el 21 de setembre (equinoccis) a totes les ciutats hi ha $12 \mathrm{~h}$ de llum solar i $12 \mathrm{~h}$ de nit. Un fet que crida l'atenció és que a Libreville tot l'any hi ha $12 \mathrm{~h}$ de sol.

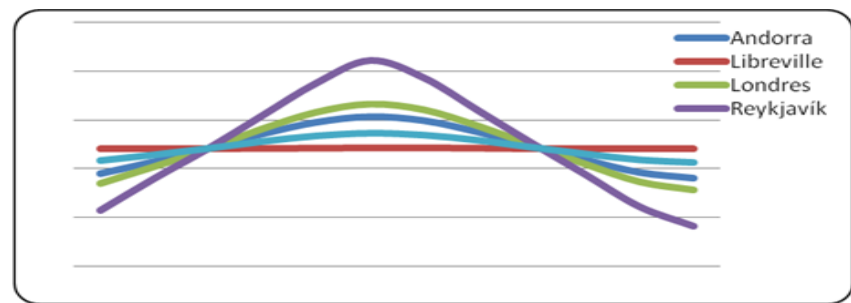

Figura 4. Gràfic comparatiu de les hores de llum solar a les ciutats estudiades

4) Cercar. Els alumnes van buscar a Internet la temperatura mitjana mensual (www.weatherbase.com ) de cadascuna de les quatre ciutats i les coordenades (www.mapcoordinates.net/es ) de cada ciutat.
5) Creuar dades. Combinant les hores de Sol amb la temperatura mitjana mensual de cada ciutat els alumnes van obtenir els gràfics següents:

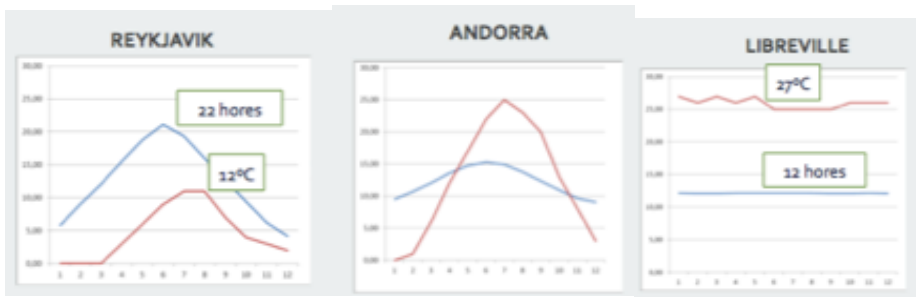

Figura 5. Gràfic que combina hores de llum solar amb temperatura mitjana

Amb els gràfics elaborats els va ser fàcil deduir que d'una manera global més hores de Sol (llum solar) no és sinònim de més calor, ja que si ens fixem en les dues ciutats més extremes de latitud (Reykjavík, de màxima latitud, i Libreville, de mínima latitud) veiem que Reykjavík a l'estiu (juny/juliol) és la que té més hores de Sol (més de 20) i la temperatura mitjana hi és molt baixa (uns $10^{\circ} \mathrm{C}$ ); en canvi, Libreville té menys hores de Sol (unes 12) i la temperatura mitjana hi és més alta (un $25^{\circ} \mathrm{C}$ ). Així doncs, tot i que les hores de Sol influeixen en la temperatura, no són un factor determinant. La conclusió de la hipòtesi (2) va ser Sí, PERÒ... Les hores de Sol són un factor que cal tenir en compte, però NO són el factor el factor determinat. Havien d'investigar més.

\section{Hipòtesi (3): Perquè els rajos solars són més inclinats?}

L'angle d'inclinació de l'eix terrestre $\left(23,5^{\circ}\right)$ també és el responsable que l'angle d'incidència del rajos solars variï al llarg de l'any. Hi ha una màxima perpendicularitat a l'estiu (21 de juny) i una mínima perpendicularitat a l'hivern (21 de desembre).

L'experiment 3.1 (esfera celeste a la taula) tenia per objectiu representar sobre una semiesfera transparent, que simula l'esfera celeste, la trajectòria de Sol en quatre dates concretes, que es corresponen amb els canvis d'estació): 21 de setembre, 21 de desembre, 21 de març i 21 de juny. L'experiment va requerir del següent material: una semiesfera transparent, una taula de fusta, un paper blanc per folrar la taula i una brúixola. El procediment seguit va ser el següent:

1) Encomanar feina. Els alumnes de $2 n$ de secundària van encomanar als alumnes d'infantil 5 que fessin el seguiment de l'evolució del Sol a 
cada canvi d'estació i la plasmessin en una semiesfera transparent on havien d'anar enganxant gomets. Van col-locar la semiesfera sobre el paper de tal manera que la intersecció dels punts cardinals fos el centre de la semiesfera $i$ fer coincidir els punts marcats a la semiesfera amb la línia Nord-Sud dels punts cardinals.

2) Experimentar aconseguint dades directament de la natura. Durant tot el dia (de 10h a 17h aprox.) els dies: 21 de desembre, 21 de març, 21 de juny i 21 de setembre, a cada hora (aproximadament) van determinar el punt (amb un llapis) de la superfície de la semiesfera que projecta l'ombra al centre de la semiesfera. En aquests punts hi van enganxar un gomet groc que simulava el Sol. La seqüència de gomets havia de representar la trajectòria del Sol al llarg de cadascun d'aquests dies.

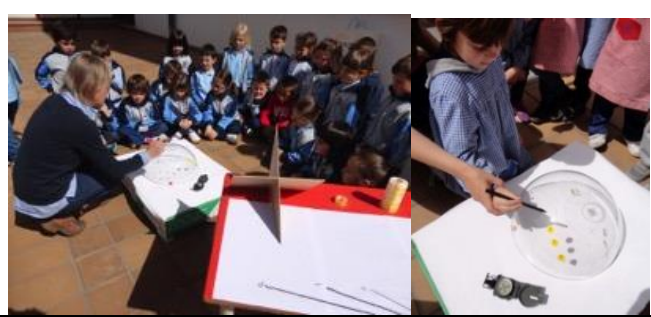

Figura 6. Alumnes d'Infantil 5 enganxen els gomets que senyalaven la trajectòria

Després de fer les 4 trajectòries els alumnes van observar que la trajectòria és mínima el 21 de desembre, és màxima sense arribar a ser perpendicular el 21 de juny i és intermèdia el 21 de març i el 21 de setembre (en què coincideix). També es van adonar que en un mateix dia el Sol va agafant altura fins al migdia (12 h del Sol) i després va perdent altura.

L'experiment 3.2 (angle d'incidència dels rajos solars) consistia en observar com varia la longitud de l'ombra de tres pals que mesuren 30,60 i 90 $\mathrm{cm}$ al llarg de l'any concretament els dies 21 de desembre, març $\mathrm{i}$ juny. El material que es va utilitzar va ser: tres pals rectes i fins de longituds diferents $(30,60,90 \mathrm{~cm})$, un suport per aguantar els pals verticalment, una cinta mètrica o regle, transportador d'angles, paper blanc i una brúixola. El procediment seguit va ser el següent:

1) Mesurar. Van mesurar les diferents ombres els dies de canvi d'estació a les 12 hores solars (12 $\mathrm{h}$ del Sol, les $13 \mathrm{~h}$ oficials en horari d'hivern i les $14 \mathrm{~h}$ en horari d'estiu) els dies 21 de desembre, 21 de març 21 de juny i 21 de setembre. Amb un brúixola indicaven la direcció de l'ombra al migdia.

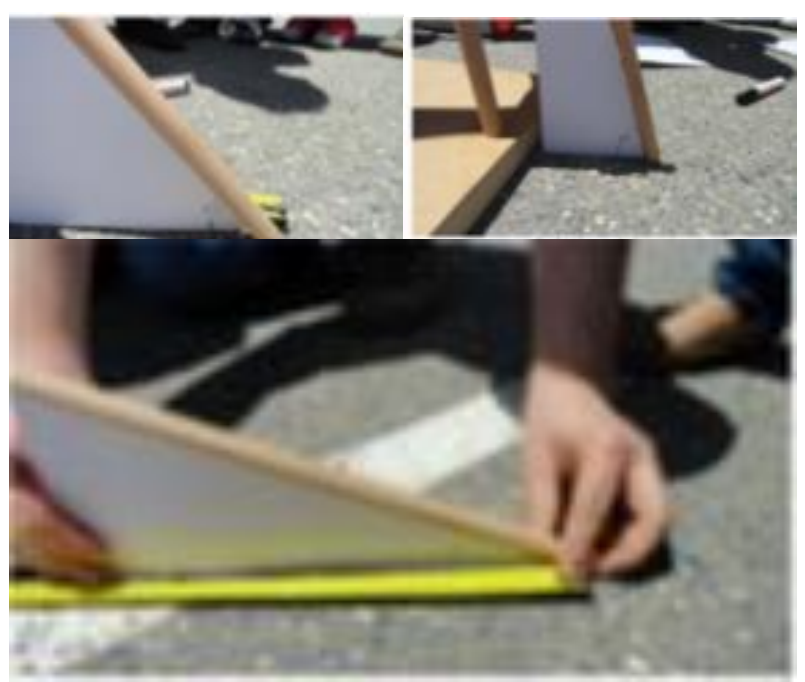

Figura 7. Alumnes de $4 \mathrm{t}$ de secundària comuniquen els resultats als alumnes d'Infantil 5 .

2) Calcular. Un cop marcada l'ombra, par a cada mesura, van dibuixar els triangles pal-ombra i van mesurar-ne els angles.

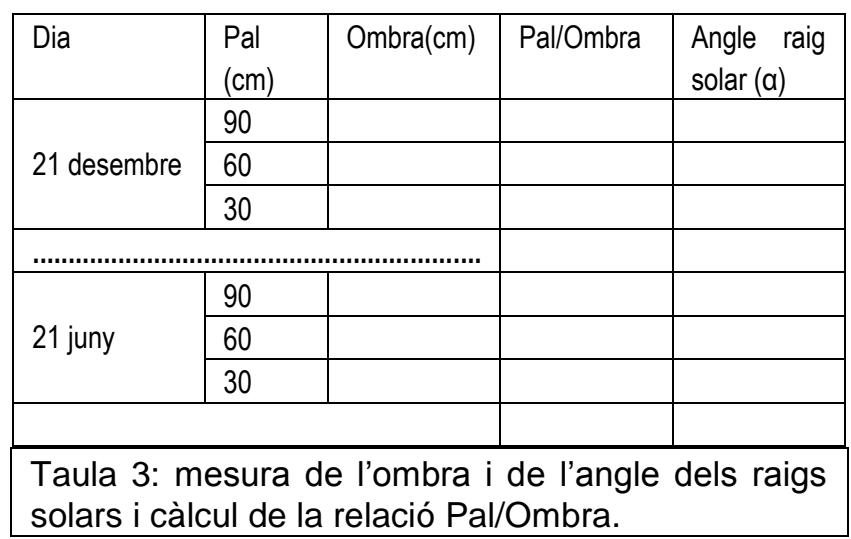

Les conclusions a les quals van arribar els alumnes van ser: 1) la diferència entre dues estacions és 23,5 , que coincideix amb l'angle d'inclinació de la Terra respecte a l'eclíptica i 2) amb aquest experiment van constatar com varia la inclinació dels rajos solars i es van adonar que a mesura que ens apropem a l'estiu l'ombra del migdia és cada vegada més curta fins a fer-se mínima el 21 de juny (que és quan el Sol està més amunt i els rajos solars cauen més verticals).

L'experiment $\mathbf{3 . 3}$ (llum i ombra) va consistir en observar om varia la zona il-luminada per una llan- 
terna en funció de la perpendicularitat del raig lluminós. El material que es necessita per fer aquest experiment és: una llanterna amb enfocament manual que permeti concentrar la il·luminació, un paper quadriculat $1 \mathrm{~cm} \times 1 \mathrm{~cm}$ i mig cèrcol (hula-hoop). L'experiment va constar de dues fases:

1) Preparar l'experiment. Els alumnes de $3 r$ de primària van preparar una quadrícula d'1 cm per 1 $\mathrm{cm}$.

2) Observar. Havien de fixar una llanterna a la meitat d'un cèrcol confeccionat amb mig hula-hoop, col-locar-lo sobre la quadrícula i il-luminar-la en diferents posicions (des de la perpendicular fins a cada vegada més inclinat).

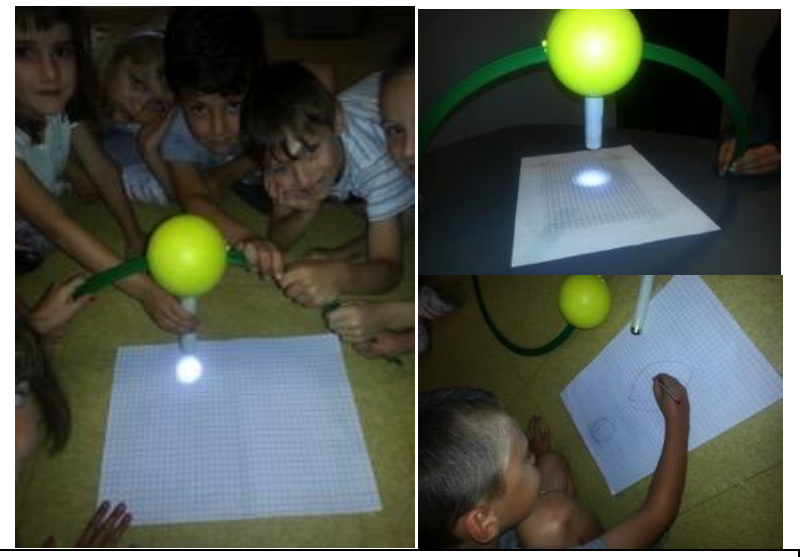

Figura 8: Els alumnes de $3 r$ de Primària preparen l'experiment

Els alumnes van arribar a la conclusió que Com menys superfície il-luminada hi ha a la quadrícula, moment en què la llanterna està perpendicular, més concentració d'energia i, per tant, més escalfor. Per tant, es verificà la hipòtesi.

\section{Conclusions finals}

Després d'efectuar tots els experiments, els alumnes van extreure conclusions finals per a cadascuna de les hipòtesis. Per a la hipòtesi 1, els alumnes van demostrar que aquesta hipòtesi és falsa. Encara que sembli contradictori, la Terra està més lluny del Sol a l'estiu que a l'hivern. Per a les hipòtesis 2 i 3, la conclusió obtinguda va ser que a l'estiu com més latitud, més hores de Sol, menys angle d'incidència del rajos solars, menys altura del sol al migdia més superfície il-luminada, menys energia solar per unitat de superfície, menys calor. En canvi, com menys latitud, menys hores de sol, més angle d'incidència del rajos solars, més altura del sol al migdia, menys superfície il-luminada, més energia solar per unitat de superfície, més calor. Això els va permetre arribar a la conclusió final següent: dels dos factors estudiats, "més hores de sol" i "rajos solars més inclinats", el factor determinant és "rajos solars més inclinats".

\section{VALORACIÓ DE L’EXPERIÈNCIA}

Els mestres i els professors que han dut a terme l'experiència l'han valorat molt positivament. Destaquem alguns aspectes de la seva valoració guarnits de perles dites pels protagonistes del projecte: els nens i les nenes del col-legi.

El nen de 3r de primària que va dir: "Quan tornem del pati continuarem buscant ciutats on ara sigui hivern?"; o el nen de 6è de primària que, després d'una sessió, va dir: "Em fa mal el cap de tant pensar, però el pròxim dia continuem amb aquestes classes, que m'agraden!".

El nen d'infantil que va dir a casa: "és que la Terra és molt petita, no ho sabeu?"; o el nen de $3 r$ de primària que setmanes després recordava que "la llum triga a arribar del Sol a la Terra 8 minuts i 20 segons, que ho van dir els grans, que caminaven del Sol a la Terra a poc a poc."

Una nena de 6è de primària, després d'explicar el projecte al Congrés de ciència de la Universitat dels Infants i a dos cursos més, va dir: "cada vegada ens surt millor", i vam poder constatar l'orgull que es reflectia a la cara dels nens quan explicaven el que havien après a nens més grans o més petits que ells.

Uns nens de $3 r$ de primària van anar a demanar ajuda a una professora de secundària i després ho explicaven emocionats i sentint-se importants -"ens ho explicat una professora dels grans a nosaltres!"; i quan un professor de la Universitat va explicar la distància entre el Sol i la Terra, un nen d'infantil va explicar: "va venir un senyor científic i ens ho va explicar".

Totes aquestes reflexions han deixat un regust de feina ben feta, la decisió de continuar treballant i també les ganes de fer-ho millor. Ens proposem corregir els aspectes millorables que hem detectat gràcies a la reflexió posterior. Són idees que es comencen a cuinar i que veuran la llum els propers cursos.

\section{REFERÈNCIES}

DURAN, D. \& VIDAL, V. (2004). Tutoría entre iguales: de la teoria a la pràctica. Barcelona: Graó. 
MOLINA, M., CASTRO, E., MOLINA, J. L., \& CASTRO, E. (2011). Un acercamiento a la investigación de diseño a través de los experimentos de enseñanza. Enseñanza de las ciencias: revista de investigación y experiencias didácticas, 29(1), 75-88.

PUJOLÀS, P. (2002). Aprendre junts alumnes diferents. Vic: Eumo Editorial.
RODRÍGUEZ, L. M., \& ESCUDERO, T. (2000). Interacción entre iguales y aprendizaje de conceptos científicos. Enseñanza de las Ciencias, 18(2), 255-274.

VALVERDE, G. (2014). Experimentos de enseñanza: una alternativa metodológica para investigar en el contexto de la formación inicial de docentes. Revista Electrónica Actualidades Investigativas en Educación, 14(3), 1-20. 